This item was submitted to Loughborough's Research Repository by the author.

Items in Figshare are protected by copyright, with all rights reserved, unless otherwise indicated.

\title{
Sport and body cultures in east and south-east Asia
}

PLEASE CITE THE PUBLISHED VERSION

http://dx.doi.org/10.1080/21640599.2017.1293898

\section{PUBLISHER}

(C) Taylor \& Francis (Routledge)

\section{VERSION}

AM (Accepted Manuscript)

\section{PUBLISHER STATEMENT}

This work is made available according to the conditions of the Creative Commons Attribution-NonCommercialNoDerivatives 4.0 International (CC BY-NC-ND 4.0) licence. Full details of this licence are available at: https://creativecommons.org/licenses/by-nc-nd/4.0/

\section{LICENCE}

CC BY-NC-ND 4.0

\section{REPOSITORY RECORD}

Trotier, Friederike, and Alan Bairner. 2019. "Sport and Body Cultures in East and South-east Asia". figshare. https://hdl.handle.net/2134/24629. 


\section{Editorial}

\section{Sport and Body Cultures in East and South East Asia}

Friederike Trotier (Goethe University Frankfurt, Germany) and Alan Bairner (Loughborough University, UK)

Welcome to the first issue of Volume 6 of the Asia Pacific Journal of Sport and Social Sciences. It has been an interesting few months for the journal as we are now accepting submissions via Editorial Manager only and the number of submissions received is steadily increasing. It is a pleasure to introduce this special issue which is the product of the scholarship of authors based in nine different countries - Australia, Germany, Hong Kong Special Administrative Region (SAR), Japan, Singapore, Taiwan, The Netherlands, the United Kingdom and the United States of America. In addition, their collective efforts address themes relating to sport and body cultures in eight different countries - Hong Kong SAR, Indonesia, Macau SAR, Papua New Guinea (formerly Netherlands New Guinea), People’s Republic of China, Singapore, South Korea, and Taiwan.

In the opening article, Friederike Trotier examines the manner in which a city - in this particular case Palembang in Indonesia - can benefit as a consequence of hosting multinational sport events. In this instance, the main benefit has been to improve the image of a city which, despite a long and relatively illustrious history, had acquired a reputation for being chaotic, dirty and backward, its inhabitants perceived as aggressive, treacherous and criminal. Trotier traces the transformation of Palembang into a city with a national and international reputation as a sports event destination. 
Marcus Chu's article also addresses issues related to hosting major sports events. Specifically his focus is on the hosting of the East Asian Games by two Chinese administrative regions, Macau and Hong Kong, and one municipality, Tianjin. Although no doubt hosting the event was linked in each place, albeit to varying degrees, to a desire to enhance the image of the host, whereas Macau put on a relatively extravagant show and Hong Kong a more conservative one, Tianjin's hosting can be described as positively frugal. Chu argues that domestic concerns and influences help to explain the different approaches taken by the three hosts.

The next two articles turn our attention towards body cultures more generally and away from sport per se even though sport, as commonly understood, remains an element of the second of these contributions. First, Yuchi Chang examines the growing interest in Taiwan in belly dancing. The women who participate in this activity, once regarded as foreign and, to a certain extent, exotic, do so for variety of reasons, including the pursuit of weight-loss and body-shaping. However, as Chang demonstrates, the popularity of belly dancing in Taiwan also reflects ideas of Chinese medicine and provides insights into the roles played not only by public health promotion but also by community universities.

Roger Casas writes about a very different population in his article addressing the cultivation of the body and sport practices among the Tai Lue Buddhist monks of Sipsong Panna in south west China. Casas describes the various ways in which forms of masculinity and of the male body are cultivated. However, in terms of sport, his focus is on the playing of basketball by the monastics. Casas argues that their enthusiasm for the sport should not be seen as a corruption of the monastic way of life but rather as a fundamental part of it. He calls for 
greater attention to be paid to the overall care for the body in the unfolding of monastic identities.

The remaining three articles in this special issue examine different organisations within which sport and other forms of physical activities are practised. Jelle Zondag outlines the role played by the scouting movement in Netherlands New Guinea from 1950 until 1962.

Alongside the traditional aims of youth organisations to encourage, health, independence and confidence among young people, the Dutch colonialists also saw the movement as a vehicle for the civilising, or arguably the subordination, of local peoples and for unifying different tribes. As some Papuans subsequently came to realise, however, movements of this sort can also be used in more counter-hegemonic ways to promote self-government and independence.

The concluding articles both focus on community sport clubs, in Singapore and South Korea respectively. Wai Cheong Chew, Ho Jin Chung and Jung Woo Lee examine the role played by such clubs in the sport development of Singapore. Their story is a relatively positive one with community clubs having played a significant role in ensuring relatively high participation rates. However, they also note that this role is diminishing with the social capital clubs previously garnered now going largely to state-supported programmes. In their examination of community sport clubs in South Korea, Sungwon Kim, Todd Seidler, Daniel Connaughton and John Spengler address a more specific concern, namely risk management practices or lack thereof in the clubs. They argue that risk management policies and practices are not conducted in a consistent manner in the clubs despite the fact that most managers are aware of a significant number of sport club-related injuries. This is a salutary reminder that, as people are encouraged to play sport and more generally to be physically active, there are 
always potential pitfalls which governing bodies and those charged with implementing their strategies ignore at their peril and to the risk of participants.

Despite a widely-held, and not entirely erroneous, view that the cultures of east and south east Asia commonly favour the mind over the body or, at least mental activity rather than physical endeavour, this special issue sheds light of the wide range of diverse ways in which sport and body cultures feature in that part of the world. This is consistent with the main aim of the Asia Pacific Journal of Sport and Social Science and we are grateful to all of the contributors to this special issue for supporting that aim through their admirable research..

We hope that you enjoy reading the contributions to this special issue and that you will not only consider submitting your own work to the journal at some stage but will also spread the word about the APJSSS and encourage friends and colleagues to read the journal, to subscribe to it and to submit their work for publication.

Friederike Trotier

Goethe-University Frankfurt, Germany

trotier@em.uni-frankfurt.de

\author{
Alan Bairner \\ Loughborough University, UK \\ A.E.S.Bairner@lboro.ac.uk
}

